
journal by the Ministry of Research-Technology and Higher Education Republic of Indonesia: No. 28/E/KPT/2019 [SINTA-5]

\title{
Desain dan Peran Collaborative Governance Penanggulangan Tindak Pidana Kekerasan dalam Rumah Tangga di Kota Surabaya
}

Design and Role of Collaborative Governance in Handling Crime of Domestic Violence in the City of Surabaya

${ }^{\square}$ Makhfudz

Badan Pegembangan Sumber Daya Manusia Provinsi Jawa Timur, Indonesia

DOI: $10.32781 /$ cakrawala.v15i1.372

\begin{tabular}{l}
\hline ARTICLE INFO \\
Collaborative Governance, \\
KDRT, \\
Surabaya. \\
Article History:
\end{tabular}

Received : 20 April 2021

Accepted : 16 Juni 2021

Publish : 17 Juni 2021

\section{Abstrak:}

Tujuan penelitian ini adalah untuk mengetahui desain dan peran collaborative governance terkait penanggulangan KDRT di Kota Surabaya. Metode penelitian ini menggunakan pendekatan studi kasus (case study) terkait dengan KDRT di Kota Surabaya. Teknik pengumpulan data dilakukan dengan cara observasi dan menggunakan kuesioner.Hasil penelitian menjelaskan bahwa desain collaborative governance dalam penanggulangan KDRT di Kota Surabaya hampir melibatkan semua Organisasi Perangkat Daerah (OPD) kota Surabaya hingga tingkat kelurahan, pihak swasta dan lembaga swadaya masyarakat. Collaborative governance dalam penanggulangan KDRT di Kota Surabaya diwujudkan dalam bentuk Tim Pusat Pelayanan Terpadu Perlindungan Perempuan dan Anak (TP2TP2A) Kota Surabaya. Bentuk collaborative governance juga mengatur tugas dan kewajiban dari masing-masing bagian, sehingga kinerja dari TP2TP2A Kota Surabaya lebih efektif dalam penanggulangan KDRT di Kota Surabaya. Pada penelitian ini ditemukan adanya faktor unik yang mendukung berjalannya collaborative governance, yaitu faktor figur pimpinan yang salah satunya diwujudkan dalam bentuk facilitative leadership/kepemimpinan fasilitatif.

\section{Abstract:}

The purpose of this study was to determine the design and role of collaborative governance related to the prevention of domestic violence in the city of Surabaya. This research method uses a case study approach (case study) related to domestic violence in the city of Surabaya. The data collection technique was carried out by means of observation and using a questionnaire. The results of the study explained that the collaborative governance design in the prevention of domestic violence in the city of Surabaya almost involved all Regional Apparatus Organizations (OPD) of the city of Surabaya to the village level, the private sector and non-governmental organizations. Collaborative governance in the prevention of domestic violence in the City of Surabaya is manifested in the form of the Integrated Service Center Team for the Protection of Women and Children (TP2TP2A) in the City of Surabaya. The form of collaborative governance also regulates the duties and obligations of each division, so that the performance of the Surabaya City TP2TP2A is more effective in tackling domestic violence in the City of Surabaya. In this study, it was found that there are unique factors that support collaborative governance, namely leadership figures, one of which is manifested in the form of facilitative leadership.

\footnotetext{
Corresponding author :

Address $\quad$ : Jl. Balongsari Tama, Gadel, Kec. Tandes, Kota SBY, Jawa Timur 60186

Email : makhfudzain@gmail.com
} 


\section{PENDAHULUAN}

Tantangan VUCA Volatile (bergejolak), Uncertain (tidak pasti), Complex (kompleks), dan Ambigue (tidak jelas) ini ditandai dengan perkembangan teknologi yang sangat cepat, informasi yang mudah tersebar, mobilitas penduduk yang semakin bebas, kondisi alam yang rentan dengan bencana serta pandemik covid-19 yang belum berhenti (Binar, 2020). Kondisi VUCA ini juga dihadapi oleh pemerintah daerah yang semakin kompleks dan semakin sulit untuk diselesaikan sendirian oleh pemerintah sehingga perlu sinergi dan kontribusi dari berbagai pihak dalam penanganan masalah publik.

Keterlibatan berbagai pihak untuk menyelesaikan permasalahan yang dihadapi sering disebut sebagai bentuk kolaborasi (Sururi, 2018). Keterlibatan instansi pemerintah, swasta dan lembaga swadaya masyarakat disebut sebagai bentuk collaborativegovernanceuntukmenyatukan beberapa pemangku kepentingan (Alfiana et al., 2021). Collaborative governance merupakan sebuah pengaturan untuk mengatur satu atau lebih lembaga publik yang terlibat secara langsung dengan pemangku kepentingan non-publik. Untuk proses pengambilan keputusan kolektif bersifat formal, berorientasi konsensus, dan musyawarah dengan tujuan untuk membuat atau mengimplementasikan kebijakan publik/mengelola program/aset publik (Ansel dan Gash, 2007). Pola dari collaborative governance juga bertujuan untuk penguatan kelembagaan dalam mencapai tujuan bersama (Kurniasih $d k k$., 2017).

Bentuk collaborative governance, diharapkan menghasilkan sinergi dalam bentuk kerjasama antar pemangku kepentingan untuk mengatasi masalah yang kompleks melalui pengambilan keputusan kolektif dan implementatif (Fadli \& Nurlukman, 2018). Collaborative governance memiliki kekuatan dalam menyelesaikan masalah, karena dalam proses kolaborasi didalamnya terdapat dialog yang memerlukan partisipasi dari pemangku kepentingan (Furqoni $d k k$., 2019). Hasil dari dialog menjadi keputusan yang telah disepakati bersama dan akan membangun kepercayaan serta membentuk komitmen terhadap proses yang akan dilaksanakan (Muhammad dkk., 2017).

Terkait dengan konsep ini peneliti tertarik untuk mempelajari bagaimana desain dan peran collaborative governance dalam penanganan kasus KDRT yang ada di Kota Surabaya Jawa Timur. Mengingat bahwa kasus KDRT yang ada di Indonesia masih menjadi masalah yang sangat serius, begitu juga dengan masalah KDRT di Jawa Timur.

Berdasarkan data dari Kasubdit Renakta Polda Jawa Timur, menunjukkan bahwa kasus KDRT di Jawa Timur mengalami kenaikan yang signifikan dari tahun 2017 sampai dengan tahun 2019. Angka kenaikan kasus KDRT di tahun 2017 terdapat 5 kejadian, tahun 2018 terdapat 13 kejadian, tahun 2019 terdapat 27 pelaporan kasus KDRT. Disisi lain, dengan adanya kesadaran masyarakat terhadap masalah KDRT maka angka pelaporan kasus KDRT menjadi meningkat. Pelaporan kasus KDRT di Jawa Timur cukup beragam, yaitu terkait dengan kasus setubuh, pencabulan terhadap anak, penganiayaan dan sebagainya

Kondisi berbeda dialami di Kota Surabaya, dimana kasus KDRT mengalami penurunan. Angka kasus KDRT yang menurun di Surabaya ini menarik untuk dikaji agar dapat dijadikan model strategi pencegahan KDRT di wilayah-wilayah lainnya. Strategi untuk menurunkan angka KDRT di Surabaya tidak terlepas dari kebijakan pemerintah dalam penangananan masalah KDRT, salah satunya penerapan collaborative governance.

Dari penelitian terdahulu, diketahui bahwa tindak pidana KDRT dibeberapa kasus di Indonesia didominasi oleh 
permasalahan ekonomi (Setiawan $d k k$., 2018). Faktor penyebab KDRT lainnya yaitu perbedaan tingkat pendidikan, kondisi ekonomi, perilaku suami, dan faktor psikologis (Basri $d k k$., 2018). Pada tataran lingkungan sosial dan hukum, kekerasan dalam rumah tangga juga disebabkan oleh faktor penegakan hukum, serta masih rendahnya pengetahuan hukum korban, masalah budaya patriarki, kondisi ekonomi atau kemiskinan, lingkungan sosial, serta kebiasaan minuman keras yang dilakukan pelaku KDRT (Sutiawati dan Mappaselleng, 2020). KDRT terbukti berdampak negatif baik terhadap anak maupun perempuan, misalnya dampak psikologis berupa hilangnya kepercayaan terhadap diri sendiri, trauma jika melihat kejadian yang mirip dengan kejadian yang dialami, dan merasa takut melakukan aktivitas seharihari (Maisah dan Yenti, 2016) there are 98 cases of domestic violence that occurred throughout 2015, both physical and psychological violence. The factors causing these violences are ranging from economic problems $(65 \%$. Tindak kekerasan juga mengakibatkan kesehatan reproduksi terganggu secara biologis yang pada akhirnya mengakibatkan terganggunya secara sosiologis. Istri yang teraniaya sering mengisolasi diri dan menarik diri karena berusaha menyembunyikan bukti penganiayaannya (Sutrisminah, 2010).

Dari berbagai temuan tersebut, penulis berargumentasi, tindak pidana KDRT merupakan permasalahan yang kompleks, yang dapat dipicu dari berbagai permasalahan lainnya, seperti ekonomi, latar belakang pendidikan, latar belakang keluarga, dan perilaku dalam masyarakat. Oleh karena itu penanggulangan tindak pidana KDRT tidak dapat dilakukan oleh pemerintah sendiri, organisasi masyarakat, tokoh masyarakat sendiri, ataupun para perempuan sendiri. Namun ketiganya perlu bersinergi untuk dapat mencegah maupun melindungi korban tindak pidana KDRT tersebut melalui penerapan collaborative governance (Duadji dan Tresiana, 2018).

Konsep collaborative governance yang dapat merepresentasi praktik terbaik kolaborasi antara organisasi pemerintah, masyarakat, dan non pemerintah lainnya dalam memecahkan masalah publik (Febrian, 2016; Mafaza \& Setyowati, 2020; Nasrulhaq, 2020). Collaborative governance yang dilaksanakan pemerintah Kota Surabaya melalui TP2TP2A memiliki kekuatan dan peran penting terhadap masalah KDRT dan kolaborasi ini diduga mampu menurunkan angka KDRT yang ada di Kota Surabaya.

Dari hasil kajian empiris serta analisis awal penulis, untuk mengarahkan karya tulis ini agar memiliki kebaruan kontribusi maka tulisan ini akan mengisi kekosongan literatur yang menjelaskan secara sistematis bagaimana desain dan peran collaborative governance dalam penanggulangan tindak pidana KDRT di Kota Surabaya.

Tujuan penelitian ini adalah untuk mengetahui desain dan peran collaborative governance terkait penanggulangan KDRT di Kota Surabaya.

\section{TINJAUAN PUSTAKA \\ Collaborative Governance}

Collaborative governance merupakan proses dan struktur dari pengambilan keputusan publik serta manajemen dengan melibatkan masyarakat secara konstruktif antar instansi publik dari berbagai level pemerintahan publik, privat dan sipil untuk melaksanakan suatu tujuan bersama yang tidak dapat dicapai kecuali dengan forum bersama (Emerson $d k k ., 2012$ ).

Collaborative governance memiliki penekanan kolaborasi yang bersifat sukarela dengan hubungan horizontal antara partisipan multisektor. Pekerjaan dalam kolaborasi sering melampaui kapasitas dan peran organisasi publik tunggal, dan membutuhkan interaksi diantara berbagai organisasi yang terkait dan terlibat dalam 
kegiatan publik (Hermansyah $d k k$., 2020), (Nopriono dan Suswanta, 2019). Kolaborasi sangat memungkinkan pemerintahan menjadi terstruktur, sehingga efektif memenuhi meningkatnya permintaan yang timbul dari pengelolaan antar pemerintah, organisasi, dan lintas sektoral (Hidayat dan Syamsuddin, 2020).

\section{Parameter Keberhasilan Collaborative Governance}

DeSeve mengidentifikasi delapan indikator dalam mengukur keberhasilan sebuah kolaborasi dalam pemerintahan, antara lain:

a. Networked structure atau struktur jaringan

b. Commitment to a common purpose atau komitmen terhadap tujuan

c. Trust among participants atau kepercayaan

d. Governance

e. Access to authority atau akses terhadap kekuasaan

f. Distributive responsibility atau pembagian akuntabilitas

g. Information sharing atau berbagi informasi

h. Access to resources atau akses terhadap sumber daya. (DeSeve, 2009), (Sepriandi dan Hussein, 2019) \& (Thomson et al., 2009).

Banyaknya parameter dalam collaborative governance membuktikan konektivitas antar instansi, sehingga kolaborasi ini dapat berjalan dengan baik (Widianti, 2020).

\section{Tindakan Pencegahan dan Perlindungan Perempuan dan Anak berdasarkan Peraturan Pemerintah}

Penyelenggaraan perlindungan perempuan dan anak korban kekerasan memiliki tujuan untuk memberikan perlindungan dan pelayanan terhadap korban kekerasan yang berbasis gender dan kepentingan terbaik bagi perempuan dan anak yang terjadi di rumah atau tempat umum. Kekerasan pada perempuan dan anak dapat berupa: kekerasan langsung yang memicu pada tindakan kekerasan fisik/psikologi secara langsung. Kedua kekerasan tidak langsung adalah tindakan yang membahayakan manusia, dapat mengakibatkan kematian. Ketiga, kekerasan represif merupakan pencabutan hak-hak dasar selain hak untuk hidup serta hak untuk dilindungi dari kecelakaan yang termasuk pelanggaran HAM. Keempat, kekerasan alienatif merujuk pada pencabutan hak-hak individu yang lebih tinggi, misalnya nasional dan budaya termasuk HAM (Ramadhan, 2018).

\section{Kerangka Teori}

Merujuk dari berbagai literatur tersebut, maka peneliti merumuskan kerangka teori dalam penelitian ini sebagaimana dapat dilihat pada Gambar 1.

Gambar 1 mengilustrasikan adanya kontribusi keberhasilan collaborative governance yang diterapkan oleh instansi pemerintah, swasta, masyarakat dan individu terhadap penanggulangan tindak pidana KDRT dapat tercapai dengan adanya desain institusi dan kepemimpinan fasilitatif yang mampu mengundang keinginan dari berbagai pihak untuk berkontribusi dalam penanganan kasus-kasus ini.

\section{METODE PENELITIAN}

Penelitian ini merupakan studi kasus di Kota Surabaya sebagai kota yang memiliki penurunan angka Tindak Pidana Kekerasan Dalam Rumah Tangga (TPKDRT) diantara kota-kota lainnya yang cenderung meningkat. Penelitian menggunakan pendekatan kualitatif eksplanatori, berusaha menjelaskan mengapa terjadi penurunan Angka TPKDRT di Kota Surabaya dengan menggunakan konsep collaborative governance sebagai landasan teoritis. Penelitian dilakukan pada bulan Desember 2020 - Februari 2021. 

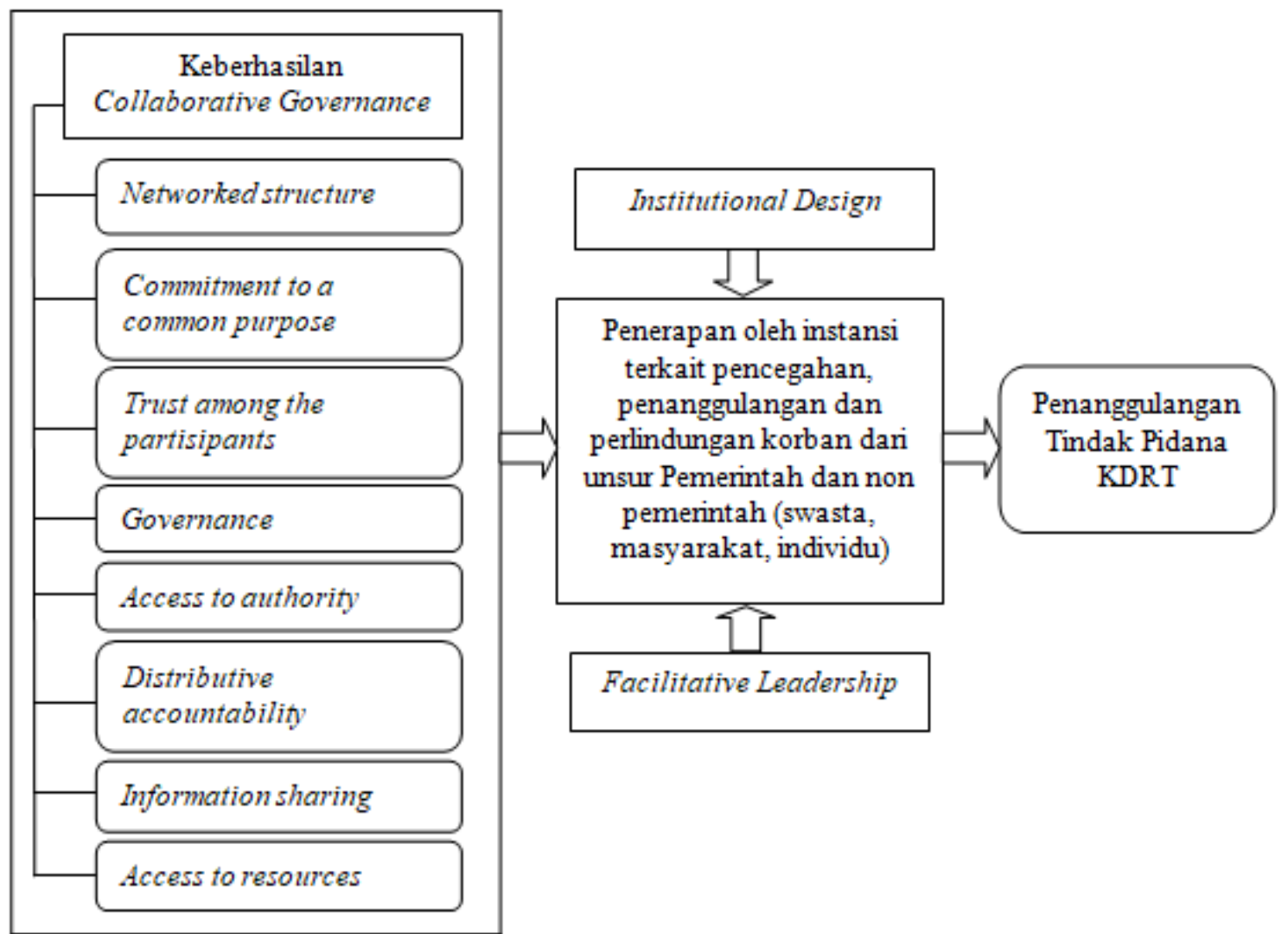

\section{Kerangka Teori Penelitian Kekerasan dalam Rumah Tangga di Surabaya}

Penelitian ini menggunakan jenis data primer dan data sekunder. Data primer berasal dari hasil wawancara. Untuk data sekunder, yaitu data yang berasal dari pustaka yang bersumber dari peraturan pemerintah daerah berupa Keputusan Walikota Surabaya Nomor 188.45/68/436.1.2/2019 tentang Tim Pusat Pelayanan Terpadu Perlindungan Perempuan dan Anak Kota Surabaya.

Teknik analisis data menggunakan pendekatan kualitatif deskriptif didesain, kemudian menghasilkan kesimpulan yang berguna untuk menjawab rumusan masalah dalam penelitian ini.

\section{HASIL DAN PEMBAHASAN \\ Desain Collaborative Governance TP2TP2A Kota Surabaya}

Desain collaborative governance terkait dengan penanggulangan masalah KDRT di Kota Surabaya bertujuan untuk menjadikan
Kota Surabaya menjadi Kota Layak Anak. Cara untuk mewujudkan keberlangsungan Kota Surabaya adalah dengan berkomitmen untuk melakukan pemenuhan hak anak dan perlindungan anak secara serius melalui kebijakan yang mendukung.

Keinginan untuk mewujudkan Surabaya menjadi Kota Layak Anak telah didukung dengan peraturan perundangundangan No 35 Tahun 2014, Perda No 6 Tahun 2011 Tentang Perlindungan Anak, serta Keputusan Walikota Surabaya Nomor 188.45/68/436.1.2/2019 terkait dengan pembentukan Tim Pusat Pelayanan Terpadu Perlindungan Perempuan dan Anak Kota Surabaya. Menurut Kepala Dinas DP5A Kota Surabaya (Ida Widayati), mengatakan bahwa beberapa tahun terakhir ini, pemerintah Kota Surabaya telah melakukan pembinaan kepada masyarakat melalui kegiatan lomba untuk mewujudkan 'Kampung Pendidikan menuju Kampung'e 
Arek Suroboyo". Tujuan dari kegiatan ini untuk menciptakan kondisi kota tinggal anak yang nyaman serta aman untuk mendukung proses tumbuh kembang anak dengan dukungan masyarakat yang menjamin pemenuhan hak anak serta mengupayakan perlindungan anak secara baik. Program kegiatan "Kampung'e Arek Suroboyo" tahun 2019 terdiri dari 5 (lima) jenis, yaitu: Kampung Belajar, Kampung Asuh, Kampung Sehat, Kampung Kreatif dan Inovatif serta Kampung Aman. Kegiatan ini menjadi salah satu program prioritas untuk menanggulangi masalah KDRT yang ada di Kota Surabaya.

Dasar hukum dari collaborative governance TP2TP2A Kota Surabaya terkait dengan upaya mengatasi tindak kekerasan terhadap perempuan dan anak di daerah Surabaya, didasarkan pada peraturan sebagai berikut:

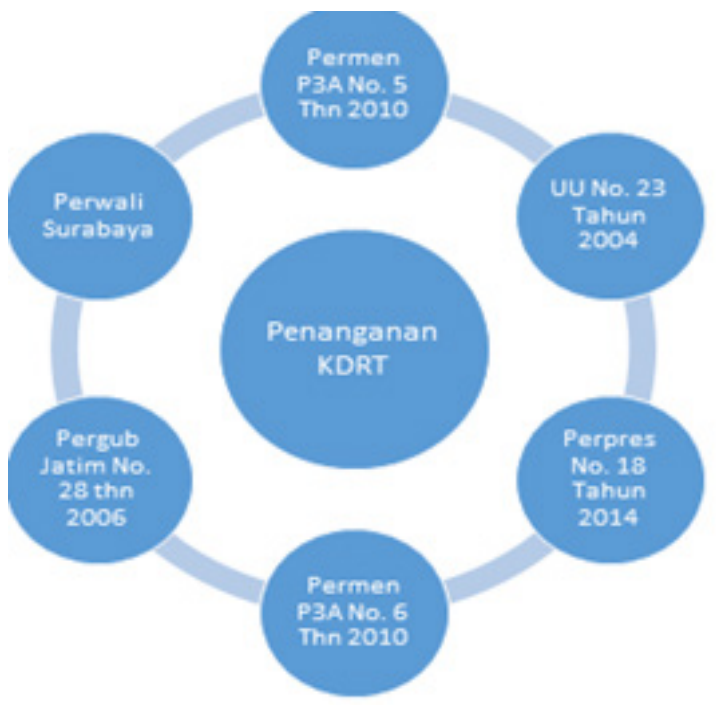

Gambar 2

Kolaborasi Peraturan dalam Penanganan KDRT di Surabaya

Setidaknya adanya enam peraturan yangmenjadidasardalampenangananKDRT di Kota Surabaya. Keputusan Walikota Surabaya Nomor 188.45/68/436.1.2/2019 tentang Tim Pusat Pelayanan Terpadu Perlindungan Perempuan dan Anak di Kota Surabaya, didasari oleh Undang-
Undang Nomor 23 Tahun 2004 tentang Penghapusan Kekerasan Dalam Rumah Tangga (Lembaran Negara Tahun 2004 Nomor 53 Tambahan Lembaran Negara Nomor 4389); Peraturan Presiden Nomor 18 Tahun 2014 tentang Perlindungan dan Pemberdayaan Perempuan dan Anak Dalam Konflik Sosial; Peraturan Menteri Negara Pemberdayaan Perempuan dan Perlindungan Anak Republik Indonesia Nomor 6 Tahun 2010; Peraturan Menteri Negara Pemberdayaan Perempuan dan Perlindungan Anak Nomor 5 Tahun 2010 tentang Panduan Pembentukan dan Pengembangan Pusat Pelayanan Terpadu; Peraturan Gubernur Jawa Timur Nomor 28 Tahun 2006 tentang Petunjuk Pelaksanaan Peraturan Daerah Provinsi Jawa Timur Nomor 9 Tahun 2005 tentang Penyelenggaraan Perlindungan Perempuan dan Anak Korban Kekerasan.

Dalam Keputusan Walikota Surabaya Nomor 188.45/68/436.1.2/2019 tentang Tim Pusat Pelayanan Terpadu Perlindungan Perempuan dan Anak di Kota Surabaya, juga mengatur adanya kolaborasi dari masing-masing dinas yang ada di Kota Surabaya, sebagai berikut:

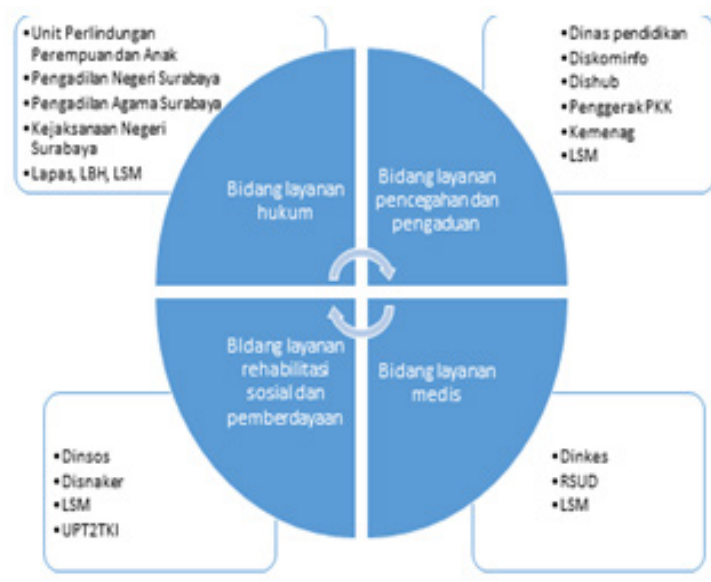

Gambar 3

Bentuk Institutional Design Kolaborasi Dinas dalam Penanganan KDRT di Kota Surabaya 
Untuk keberlanjutan tugas Tim Pusat Pelayanan Terpadu Perlindungan Perempuan dan Anak di Kota Surabaya, maka telah diterbitkan Keputusan Walikota Surabaya Nomor 188.45/68/436.1.2/2019 Tentang Tim Pusat Pelayanan Terpadu Perlindungan Perempuan dan Anak Kota Surabaya.

Keputusan Walikota Surabaya ini merupakan bentuk dari implementasi dari collaborative governance dalam penanganan tindak kekerasan terhadap perempuan dan anak di wilayah Surabaya.

Untuk collaborative governance dalam penanganan tindak kekerasan terhadap perempuan dan anak di wilayah Surabaya, maka dibuat kelompok kerja dengan ketua harian oleh Sekretaris Daerah Kota Surabaya, dan sekretaris harian oleh Kepala Dinas Pengendalian Penduduk, Pemberdayaan Perempuan dan Perlindungan Anak (DP5A) Kota Surabaya. Untuk pembagian bidang dapat dikelompokkan sebagai berikut:

- Bidang Layanan Pengaduan

- Bidang Layanan Rehabilitasi Kesehatan

- Bidang Layanan Rehabilitasi Sosial, Reintegrasi Sosial dan Pemberdayaan

- Bidang Layanan Bantuan Hukum.

Selain itu, konsep collaborative governance yang melibatkan berbagai pihak dari unsur pemerintah maupun non pemerintah. Untuk unsur pemerintah melibatkan Dinas Pengendalian Penduduk, Pemberdayaan Perempuan dan Perlindungan Anak (DP5A) Kota Surabaya, Dinas Pendidikan, Dinas Kesehatan, Dinas Sosial, Kepolisian, Kejaksanaan, Pengadilan Negeri Surabaya, Pengadilan Agama Surabaya dan dinas-dinas lainnya. Untuk unsur non pemerintah melibatkan Lembaga Swadaya Masyarakat (LSM) dan yayasan sosial yang ada di Jawa Timur. Untuk LSM yang terlibat, diantaranya: LSM Sebaya Perkumpulan Keluarga Berencana Indonesia (Sebaya PKBI) Jawa Timur, LSM Koalisi Perempuan Indonesia
(KPI) Jawa Timur, LSM ISCO Foundation, LSM Couple Community Surabaya, Ketua Lembaga Swadaya Masyarakat Savy Amira, LSM Surabaya Child Crisis Centre (SCCC). Sedangkan yayasan sosial yang terlibat dalam penanangan tindak KDRT di Kota Surabaya, diantaranya: Yayasan Surya Gemilang, Yayasan Genta, Yayasan Hotline Surabaya, Yayasan Neema Foundation, Yayasan Embun Surabaya dan Yayasan Pendidikan Alang-Alang.

\section{Peran Collaborative Governance dalam Penanggulangan Kasus Kekerasan dalam Rumah Tangga dan Anak}

Berdasarkan hasil wawancara yang dilakukan terhadap pihak-pihak yang terlibat dalam penanganan tindak kekerasan terhadap perempuan dan anak di wilayah Surabaya, maka diketahui beberapa faktor yangmendukung pelaksanaan collaboration governance di Kota Surabaya, diantaranya:

- Networked structure (struktur jaringan) Untuk penanganan masalah KDRT yang ada di Surabaya, maka telah diterbitkan SK Walikota Surabaya tentang TP2TP2A, dimana SK ini melibatkan sebagian besar OPD yang ada di Surabaya dan melibatkan pihak LSM serta organisasi kemasyarakat lainnya hingga level kelurahan. Kerja dari TP2TP2A merupakan kerja tim dari berbagai OPD di Kota Surabaya. Dalam proses kerjanya, tim ini diketuai oleh SEKDA Kota Surabaya dan untuk pelaksanaan tugas harian dibawah koordinator DP5A Kota Surabaya.

- Commitment to a common purpose (komitmen terhadap tujuan)

Kolaborasi dalam penanganan kekerasan dalam rumah tangga dan anak di Kota Surabaya memiliki tujuan untuk menurunkan angka KDRT yang ada di Kota Surabaya. Tugas ini menjadi tanggung jawab bersama melalui TP2TP2A yang selama ini bekerja dibawah arahan Ibu Risma (Walikota). 
Untuk mencapai tujuan tersebut, maka TP2TP2A yang selama ini berjalan tidak terlepas dari adanya aktor utama yang memandu jalannya kolaborasi ini, sehingga penanganan kekerasan dalam rumah tangga dan anak di Kota Surabaya dapat terkendali sesuai harapan. Arahan dari aktor utama dalam hal ini Walikota Surabaya memiliki peran penting untuk menyatukan unsur-unsur OPD dan pihak lain yang terkait, mengingat bahwa TP2TP2A merupakan tim yang besar dan terdiri dari lintas instansi.

- Trust among participants (kepercayaan) Untuk meningkatkan kepercayaan kerja tim, maka setiap tiga bulan sekali dilakukan pertemuan rutin untuk membahas masalah KDRT. TP2TP2A memiliki agenda rutin setiap tiga bulan sekali untuk berdiskusi masalah KDRT, diskusi ini juga mengundang LSM dan pihak terkait dengan masalah yang akan dibahas.

- Governance

Governance atau pola hubungan antar elemen yang terlibat dalam penanganan KDRT di Kota Surabaya. Pola hubungan dalam kolaborasi ini dituangkan dalam Keputusan Walikota Surabaya Nomor $188.45 / 68 / 436.1 .2 / 2019$ tentang Perubahan Kedua atas Keputusan Walikota Nomor 183.45/48/436.1.2/2017 tentang Tim Pusat Pelayanan Terpadu Perlindungan Perempuan dan Anak Kota Surabaya.

- Access to authority (akses terhadap kekuasaan)

Kolaborasi penanganan KDRT yang terbentuk dalam sebuah Tim Pusat Pelayanan Terpadu Perlindungan Perempuan dan Anak (TP2TP2A) yang beranggotakan dari unsur OPD dan swasta, membutuhkan adanya koordinasi yang baik dan akses informasi yang tepat. Akses informasi ini berkaitan dengan koordinasi yang dilakukan antara pimpinan OPD dengan OPD lainnya, bawahan OPD dengan pimpinan OPD yang berbeda dan sebagainya. Berdasarkan hasil wawancara diketahui bahwa akses terhadap kekuasaan untuk mendapatkan informasi terkait masalah KDRT yang ada di Kota Surabaya tidak mengalami kendala.

- Distributive accountability/ responsibility (pembagian akuntabilitas)

TP2TP2A secara khusus menanganani korban KDRT masyarakat ber-Kartu Tanda Penduduk (KTP) Surabaya, dimana untuk pembiayaan visum dibiayai oleh Pemerintah Kota Surabaya melalui DP5A. Untuk layanan kesehatan lainnya akibat KDRT bagi korban dengan kepesertaan Badan Penyelenggara Jaminan Sosial (BPJS) Kesehatan Mandiri tidak dapat ditanggung BPJS, sedangkan untuk masyarakat miskin dan ber Nomor Induk Keluarga (NIK) Surabaya dapat dibiayai oleh Pemerintah Kota Surabaya. Kebijakan ini diambil bertujuan untuk meningkatkan akuntabilitas TP2TP2A Kota Surabaya.

- Information sharing(berbagi informasi) Berbagi informasi digunakan untuk bahan koordinasi antar OPD maupun dengan pihak swasta. Informasi yang diberikan juga tergantung tingkat urgensinya, dimana ada beberapa kasus yang hanya melibatkan kepala OPD karena kasus klien yang bersifat rahasia. Bentuk inisiasi kolaborasi yang dilakukan Tim Pusat Pelayanan Terpadu Perlindungan Perempuan dan Anak (TP2TP2A) misalnya diskusi, rapat koordinasi, anggaran, sumber daya aparatur, fasilitas lainnya yang mengacu pada RKA (Rencana Kerja dan Anggaran) masing-masing OPD. Secara berkala TP2TP2A juga membuat laporan yang ditujukan kepada Walikota dan tembusannya kepada anggota Kelompok Kerja (Pokja), 
sehingga anggota Pokja mengetahui terhadap kasus dan treatment yang sudah diberikan terkait KDRT yang terjadi di Kota Surabaya.

- Access to resources (akses terhadap sumber daya)

Bentuk kolaborasi untuk pencegahan KDRT yang dilakukan TP2TP2A lebih banyak dilakukan dalam kegiatan sosialisasi, misalnya: kegiatan sosialisasi pencegahan KDRT yang mengundang pemuka agama dari 6 (enam) agama, perwakilan organisasi wanita se-Surabaya oleh DP5A; Sosialisasi dinamika remaja di SD dan SMP Negeri/Swasta di Surabaya oleh DP5A; Capacity Building bagi relawan PKBM dan Satgas PPA yang rutin dilakukan oleh DP5A; Mengadakan kegiatan lomba KP KAS (Kampung Pendidikan Kampunge Arek Suroboyo) oleh DP5A; Membentuk Forum Anak Surabaya (FAS) di tingkat Kota oleh DP5A; Kampanye untuk mencegah KDRT (sebelum masa Pandemi Covid 19) oleh FAS; Membentuk Konselor Sebaya di setiap sekolah (SMP) oleh Dinas Pendidikan, dan sebagainya.

Peran collaborative governance yang ada di Kota Surabaya khususnya terkait dengan TP2TP2A, memberikan kontribusi terhadap penanggulangan masalah KDRT di Kota Surabaya. Masing-masing OPD memiliki peran berbeda dalam penanggulangan masalah KDRT di Kota Surabaya. Berdasarkan hasil wawancara dengan korban KDRT yang ada di Surabaya, bahwa korban telah merasakan manfaat dari collaborative governance. Sebagai contoh korban KDRT yang dialami oleh NW (istri) telah mendapat kekerasan psikis pada sekitar tahun 2019 hingga bulan April 2020 dan melaporkan kekerasan psikis pada bulan April 2020. Korban tidak berdaya ketika anak kandung korban (nama DAN) dengan tipu muslihat disetubuhi ayah tirinya bernama EW sejak usia 15 tahun hingga hamil dan melahirkan anak dan saat ini usia anak korban 17 tahun.

Dari kasus tersebut, collaborative governance telah berjalan dengan baik. Penanganan kasus ini diawali dari laporan masyarakat kepada Unit Perlindungan Perempuan dan Anak Kota Surabaya dan pihak kepolisian segera melakukan proses penyelidikan terhadap kasus tersebut. Selain itu, Dinas Pendidikan Kota Surabaya juga ikut membantu dalam penanganan kasus ini, mengingat bahwa korban KDRT masih berstatus sebagai pelajar. Dinas Pendidikan melakukan observasi terhadap korban dan melakukan koordinasi dengan Dinas Kesehatan terkait dengan rujukan ke layanan lanjutan. Dinas Kesehatan Kota Surabaya juga melakukan koordinasi dengan pihak rumah sakit terkait dengan pemeriksaan dan visum terhadap korban selanjutnya dibuat laporan kasus untuk dikoordinasikan dengan pihak kepolisian Kota Surabaya. Dalam proses hukum tersebut, korban juga mendapatkan pendampingan hukum dari Lembaga Swadaya Masyarakat Surabaya Child Crisis Centre (SCCC). Selain itu, korban KDRT juga mendapakan rehabilitasi di Shelter yang dikelola oleh Dinas Sosial Kota Surabaya. Untuk meningkatkan kemandirian korban maka Dinas Sosial bersama dengan Dinas Tenaga Kerja serta Lembaga Swadaya Masyarakat ISCO Foundation memberikan pelatihan kerja sebagai tindakan pemberdayaan korban KDRT. Kegiatan pelatihan ini juga melibatkan Ketua Tim Penggerak Pemberdayaan Kesejahteraan Keluarga (TP PKK) di tingkat Kelurahan guna mendampingi secara lebih dekat kepada korban. Selain itu, pihak DP5A juga berkoordinasi dengan pihak Ketua RT untuk membantu warga di sekitar lingkungan korban untuk ikut peduli dengan masalah yang dialami korban. Kolaborasi dari OPD dan pihak swasta merupakan bentuk 
komitmen bersama sebagai wujud dari collaborative governance yang ada di TP2TP2A Kota Surabaya.

Terkait dengan kasus yang lain, pada tahun 2019, TP2TP2A Surabaya (DP5A) menerima pengaduan dari kepala sekolah SDN Wonorejo 1 perihal salah satu muridnya yang tidak bersekolah selama satu semester. Setelah dilakukan home visit diketahui bahwa orangtua klien sudah berpisah (ayah klien menikah lagi) sedangkan ibunya mengalami gangguan jiwa, sehingga melarang klien keluar rumah dan juga melarang untuk bersekolah. Berdasarkan kasus tersebut, maka pihak guru melaporkan kepada Dinas Pendidikan Kota Surabaya untuk dilakukan penanganan lebih lanjut. Dinas Pendidikan bersama dengan Dinas Sosial melakukan observasi langsung ke rumah korban dan memberikan rekomendasi untuk dilakukan perawatan kesehatan mental kepada ibu korban KDRT. Selanjutnya Dinas Kesehatan berkoordinasi dengan RS. Dr. M. Soewandhie untuk perawatan kesehatan mental ibu klien. dan sedangkan Dinas Sosial membawa korban ke Shelter untuk dilakukan perawatan dan pemantauan perkembangan psikis anak tersebut. Selama proses berjalan, maka kasus ini tidak diteruskan kepada pihak kepolisian, mengingat bahwa pelaku KDRT mengalami gangguan jiwa dan kasus ini lebih menekankan aspek humanitis dalam penyelesaian masalahnya. Kasus ini lebih banyak melibatkan Dinas Pendidikan Kota Surabaya untuk memotivasi korban dan memberikan kesempatan pada korban untuk tidak putus sekolah dengan memberikan fasilitas sekolah gratis bagi korban. Selain itu, Dinas Sosial juga memberikan bantuan uang tunai sebesar Rp. 1.500.000,- selama proses pengawasan dan pendampingan yang dilakukan oleh LSM yang telah ditunjukkan TP2TP2A.

Bentuk kolaborasi yang dihasilkan dari collaborative governance yang ada di TP2TP2A Kota Surabaya telah banyak dirasakan oleh berbagai pihak, baik korban maupun pihak-pihak yang berkaitan dengan masalah KDRT. Sinergi kolaborasi ini menjadi penting untuk menyelesaikan permasalahan KDRT yang sangat komplek, dimana keterlibatan dari masing-masing OPD, swasta dan lembaga swadaya masyarakat sangat diperlukan.

Dari hasil pemetaan tersebut nampak bahwa teori collaborative governance dapat membantu untuk menganalisis best practices dalam penanganan KDRT. Dari praktik yang ada di Kota Surabaya, indikator keberhasilan dalam implementasi collaborative governance untuk penanganan KDRT terdapat delapan indikator yang mempengaruhi, yaitu: networked structure (struktur jaringan), commitment to a common purpose (komitmen terhadap tujuan), trust among participants (kepercayaan), governance, access to authority (akses terhadap kekuasaan), distributive accountability/ responsibility (pembagian akuntabilitas), information sharing (berbagi informasi) dan access to resources (akses terhadap sumber daya).

Dengan demikian, praktik penanganan KDRT yang sudah baik di Kota Surabaya dapat ditingkatkan lagi dengan memenuhi delapan indikator-tersebut. Adanya kekurangan dalam indikator access to authority menjadi bahan evaluasi, dimana setiap adanya pergantian kepala OPD sering menjadi masalah dalam kegiatan organisasi. Selain itu, belum adanya saluran pengaduan korban KDRT yang terpusat juga harus dipertimbangkan untuk diwujukan agar data KDRT menjadi terpusat.

Dari hasil penelitian ternyata ada beberapa praktik yang dapat menjadi improvisasi teori collaborative governance, bahwasanya terdapat praktik diluar hal tersebut, yakni: faktor publik figur. Nama Walikota Surabaya (Tri Rismaharini) selama memimpin dua periode telah 
menjadi publik figur yang dikenal dengan istilah Emak-e Arek Suroboyo, memiliki kepedulian yang luar biasa dengan masalah KDRT yang ada di Surabaya

\section{SIMPULAN}

Desain collaborative governance dalam penanggulangan KDRT di Kota Surabaya hampir melibatkan semua Organisasi Perangkat Daerah (OPD) kota Surabaya hingga tingkat kelurahan, pihak swasta dan lembaga swadaya masyarakat. Collaborative governance dalam penanggulangan KDRT di Kota Surabaya diwujudkan dalam bentuk Tim Pusat Pelayanan Terpadu Perlindungan Perempuan dan Anak (TP2TP2A) Kota Surabaya. Bentuk collaborative governance juga mengatur tugas dan kewajiban dari masing-masing bagian, sehingga kinerja dari TP2TP2A Kota Surabaya lebih efektif dalam penanggulangan KDRT di Kota Surabaya. Peran collaborative governance dalam penanggulangan KDRT di Kota Surabaya dapat dilihat dari delapan indikator, yaaitu: networked structure (struktur jaringan) dengan terbentuknya TP2TP2A, commitment to a common purpose (komitmen terhadap tujuan) dengan adanya program "Surabaya Layak Anak", trust among participants (kepercayaan) dengan adanya pertemuan rutin tim yang dilakukan tiga bulan sekali, governance, access to authority (akses terhadap kekuasaan) dan distributive accountability/responsibility (pembagian akuntabilitas) dengan tetap membiarkan masing-masing institusi berperan tanpa membentuk unit baru, information sharing (berbagi informasi) yang dilakukan dalam bentuk koordinasi dan pembagian tugas, dan access to resources (akses terhadap sumber daya) yang dilakukan dalam bentuk optimalisasi SDM untuk menekan angka KDRT. Dalam konsep collaborative governance diperlukan kepemimpinan fasilitatif. Dalam praktik di Surabaya, kepemimpinan tidak hanya fasilitatif tetapi juga memiliki kepedulian yang tinggi yang diwujudkan tidak hanya dalam bentuk kebijakan dan tetapi bahkan tindakan yang riil, yaitu melakukan pencegahan KDRT dengan melakukan sosialisasi untuk semua kalangan mulai dari anak-anak, remaja dan orangtua. Kegiatan sosialisasi dilakukan langsung oleh Walikota Surabaya (Tri Rismaharini) bersama dengan jajarannya, hal ini dilakukan untuk mencegah terjadinya KDRT yang ada di Surabaya. Langkah kedua yang dilakukan adalah penanggulangan terhadap pelaku dan korban KDRT secara langsung (tidak menunda-nunda). Semua pelaku KDRT telah diproses hukum untuk memberikan efek jera kepada pelaku dan tidak ada mediasi antara pelaku dengan korban. Langkah ketiga adalah perlindungan korban, selama ini pemerintah Kota Surabaya memberikan fasilitas shelter bagi korban KDRT. Korban yang ditampung dalam shelter untuk menjamin keamanan korban dan korban tetap mendapatkan bimbingan dari petugas shelter dan ada beberapa korban KDRT yang berprestasi setelah tinggal di shelter. Selain itu, korban KDRT juga mendapatkan bantuan uang tunai dari pemerintah Kota Surabaya dengan tujuan untuk mengentaskan kemiskinan yang dialami korban KDRT.

\section{DAFTAR PUSTAKA}

Alfiana, Alwi, Susanti, G. (2021). Collaborative Governance dalam Pengelolaan Sumber Daya Perikanan Untuk Kesetaraan: Studi Kasus di Kota Makassar. 3(1), 1-18.

Ansel, C., Gash, A. (2007). Collaborative Governance in Theory and Practice. Oxford Unversity Press. 
Basri, S., Kasim, S., Roslan, S. (2018). Fadli, Y., Nurlukman, A. D. (2018.) Kekerasan dalam Rumah Tangga (KDRT) yang Dialami Suami (Studi di Desa Kontumere Kecamatan Kabawo Kabaupaten Muna). Neo Societal, 3(2), 1-26.

Binar, R. (2020). Volatility, Uncertainty, Complexity, and Ambiguity (VUCA). http://binakarir.com/ volatility-uncertainty-complexityambiguity-vuca/

Kurniasih, D. Setyoko, P. I., Imron, M. (2017). Collaborative Governance Dalam Penguatan Kelembagaan Program Sanitasi Lingkungan Berbasis Masyarakat (SLBM) di Kabupaten Banyumas. Sosiohumaniora, 19(1), 1-7. https://doi.org/10.24198/ sosiohumaniora.v19i1.7888

DeSeve. (2009). Integration and innovation" in the intelligence community: The role of a netcentric environment, managed networks, and social networks. In Goldsmith, S., \& Kettl, D. F. (Eds.), Unlocking the power of networks; keys to highperformance government. Ash Center: Brookings Institution Press., 121-144.

Duadji, N., Tresiana, N. (2018). Kota Layak Anak Berbasis Collaborative Governance. Sawwa: Jurnal Studi Gender, 13(1), 1-22. https://doi. org/10.21580/sa.v13i1.2201

Emerson, K., Nabatchi, Balogh. (2012). An Integrative Framework for Collaborative Governance. Journal of Public Administration Research and Theory. Kolaborasi Pemerintah dalam Pengembangan Terpadu Wilayah Pesisir di Kabupaten Tangerang melalui Gerakan Pembangunan Masyarakat Pantai (Gerbang Mapan). Prosiding Seminar Nasional Unimus, 1, 517-529.

Febrian, R. A. (2016). Collaborative Governance In The Development Of Rural Areas (Review of the Draft and Regulation). Wedana, II(1), 200-208. http://journal.uir. ac.id/index.php/wedana/article/ view/1824 diakses pada tanggal 5 April 2019 pukul 02:55 WIB

Furqoni, I., Rosyadi, S., Isna, A. (2019). Collaborative Governance in Corporate Social Responsibility Forum in Banyumas Regency. Jurnal Bina Praja, 11(2), 209217. https://doi.org/10.21787/ jbp.11.2019.209-217

Hermansyah, Haris, A., Amirudin. (2020). Model Kolaborasi dalam Pengembangan Parawisata di Kabupaten Sinjai. 10(2), 133-145.

Hidayat, R., Syamsuddin, S. (2020). Collaboration of Resources in Task Force for Prevention and Handling Victims of Human Trafficking in Indonesia. Otoritas : Jurnal Ilmu Pemerintahan, 10(2), 165-175. https://doi.org/10.26618/ojip. v10i2.2824

Mafaza, A., Setyowati, K. (2020). Collaborative Governance Dalam Pengembangan Desa Wisata. Jurnal Kebijakan Publik, 11(1), 7-12. https://doi.org/10.31258/ jkp.11.1.p.7-12 
Maisah, Yenti. (2016). Dampak Psikologis Korban Kekerasan Dalam Rumah Tangga Di Kota Jambi. ESENSIA: Jurnal Ilmu-Ilmu Ushuluddin, 17(2), $265 . \quad \mathrm{https}: / /$ doi. org/10.14421/esensia.v17i2.1292

Muhammad, A. S., Warsito, T., Pribadi, U., Nurmandi, A. (2017). Collaborative Governance Model in Managing International Borders in Riau Islands Province using Partial Least Squares Method. JKAP (Jurnal Kebijakan Dan Administrasi Publik), 21(2), 155167. https://doi.org/10.22146/ jkap.28097

Nasrulhaq, N. (2020). Nilai Dasar Collaborative Governance Dalam Studi Kebijakan Publik. Kolaborasi : Jurnal Administrasi Publik, 6(3), 395-402. https://doi. org/10.26618/kjap.v6i3.2261

Nopriono, Suswanta.(2019).Pemberdayaan Masyarakat Dalam Perspektif Collaborative Governance. JPK: Jurnal Pemerintahan Dan Kebijakan, 1(1), 21-36.

Ramadhan, R. A. (2018). Pengaruh Kekerasan Dalam Rumah Tangga (KDRT) terhadap tingkat keharmonisan dalam keluarga di kelurahan Umban Sari kecamatan Rumbai Kota Pekanbaru. Jom Fisip, 5(1), 1-15.

Sepriandi, S., Hussein, R. (2019). FaktorFaktor yang Mempengaruhi Collaborative Governance dalam Penanganan Pekerja Migran Bermasalah di Kota Tanjungpinang. JPPUMA Jurnal Ilmu Pemerintahan Dan Sosial Politik Universitas Medan Area, 7(1), 80-91. https://doi. org/10.31289/jppuma.v7i1.2175
Setiawan, C. N., Bhima, S. K. L., Dhanardhono, T. (2018). FaktorFaktor yang Memengaruhi Kejadian Kekerasan dalam Rumah Tangga dan Pelaporan Pada Pihak Kepolisian. Jurnal Kedokteran Diponegoro, 7(1), 127-139.

Sururi,A.(2018). Collaborative Governance Sebagai Inovasi Kebijakan Strategis (Studi Revitalisasi Kawasan Wisata Cagar Budaya Banten Lama). Humanika, 25(1), 25-37. https://doi.org/10.14710/ humanika.v25i1.18482

Sutiawati, S., Mappaselleng, N. F. (2020). Penanggulangan Tindak Pidana Kekerasan dalam Rumah Tangga di Kota Makassar. Jurnal Wawasan Yuridika, 4(1), 17. https://doi. org/10.25072/jwy.v4i1.315

Sutrisminah, E. (2010.) Dampak Kekerasan Pada Istri Dalam Rumah Tangga Terhadap Kesehatan Reproduksi. Majalah Ilmiah Sultan Agung, 50(127), 23-34.

Thomson, A. M., Perry, J. L., Miller, T. K. (2009). Conceptualizing and measuring collaboration. Journal of Public Administration Research and Theory, 19(1), 23-56. https:// doi.org/10.1093/jopart/mum036

Widianti, S. (2020). Konektivita dan Kokaborasi. Jurnal Budaya Nusantara, 4(1), 164-177. 